\title{
DEALING WITH INCOMMENSURABILITY FOR DESSERT AND DESERT: COMMENTS ON CHAPMAN AND KATZ
}

\section{BRIAN BIX $\dagger$}

Incommensurability is the claim that different choices, or different values underlying choices, cannot be measured on a single metric. ${ }^{1}$ The related, but different claim of incomparability is that there are items or choices of which it cannot sensibly be said that one is better than the other (or that the two are equally good). ${ }^{2}$

The phenomenon of incommensurability can be recharacterized as the irreducible plurality of values. The implications of incommensurability for practical reasoning, moral reasoning, and law are highly contested. Isaiah Berlin famously argued, in a series of books, that the plurality of values showed the basic flaws of monistic and Utopian strains in political thought, strains that go back to the Enlightenment and that include, in modern times, Socialism and Marxism.

† Professor of Law, Quinnipiac College School of Law. I am grateful to Claire Finkelstein, Leonard Long, and Linda Meyer for comments on earlier drafts of this piece.

'In her introduction to a collection of essays on incommensurability and incomparability, Ruth Chang defines "incommensurability" as the situation in which "items cannot be precisely measured by a single 'scale' of units of value." Ruth Chang, Introduction, in INCOMMENSURABILITY, INCOMPARABILITY, AND PRACTICAL REASON 1, 1 (Ruth Chang ed., 1997) [hereinafter INCOMMENSURABILITY].

${ }^{2}$ See id. at 2 ("Given that the two ideas are distinct, let us henceforth reserve the term 'incommensurable' for items that cannot be precisely measured by some common scale of units of value and the term 'incomparable' for items that cannot be compared." (footnote omitted)).

There are writers who use the term "incommensurability" to refer to both incommensurability and incomparability (including, unsurprisingly, some who assume or have concluded that the first entails the second), see JOSEPH RAZ, THE MORALITY OF FREEDOM 322 (1986), and there are some who use the term to refer only to what I am calling "incomparability," see, e.g., Donald H. Regan, Authority and Value: Reflections on Raz's Morality of Freedom, 62 S. CAL. L. REV. 995, 1056 (1989) (defining "incommensurability" roughly in the way this text has defined "incomparability"). As always in such matters, the labels are not crucial, as long as we can be clear about what is being discussed.

s See, e.g., ISAIAH Berlin, The CROOKED Timber of Humanity (Henty Hardy ed., 1990) (discussing, over the course of a series of essays, the history of monistic theories of truth and value, and the critiques of such theories, and ultimately siding with the critiques); ISAIAH BERLIN, THE PROPER STUDY OF MANKIND (Henry Hardy \& Roger Hausheer eds., 1997) (same); ISAIAH BERLIN, THE SENSE OF REALITY (Henry Hardy ed., 1996) (same). 
In moral reasoning, the fact of the plurality of goods is often used to argue against the possibility of utilitarianism, and its sister forms of analysis, law and economics and rational choice theory. Indeed, the phenomenon of incommensurability would appear to pose problems (though not necessarily insoluble problems) for all forms of analysis that depend on the ability to reduce all options to a single good that is being optimized, or to a single continuum of measurement. ${ }^{4}$

It is sharply contested whether incommensurability entails incomparability: that is, whether incommensurability means that one cannot speak meaningfully of one option (which instantiates one value) being better than a second (which instantiates a different value). ${ }^{5}$ The claims that choices can be incomparable, and that this sort of incomparability occurs with some frequency, would seem to threaten basic aspects of the way we think about morality, aesthetics, law, and dozens of other aspects of our lives. ${ }^{6}$

Even if incommensurability does not entail incomparability, there remain interesting connections to draw between incommensurability and moral or practical reasoning. It is tempting to ask, if options cannot be measured on a single metric, how can rational choice (understood in its colloquial, not its technical, sense) be possible? The paradoxical, but (I believe) persuasive response is that it is incommensurability that makes rational choice possible. If all options were reducible to units of some good an individual sought to maximize, there would be no need for "choice," understood as an act of

1 An example of the latter would be the indifference curve in economic thought. See Bruce Chapman, Law, Incommensurability, and Conceptually Sequenced Argument, 146 U. PA. L. REV. 1487, 1491 \& n.9 (1998).

${ }^{5}$ Compare RAZ, supra note 2, at 321-66 (equating incommensurability and incomparability), and John Finnis, Natural Law and Legal Reasoning, 38 CLEV. ST. L. REV. 1, 713 (1990) (same), with Chang, supra note 1, at 4-34 (offering extensive arguments for denying the equation of incommensurability and incomparability), and Cass $\mathrm{R}$. Sunstein, Incommensurability and Valuation in Law, 92 MICH. L. REV. 779, 803, 805-08 (1994) (denying the equation of the two concepts).

${ }^{6}$ See Chang, supra note 1, at 4-34. A similar question arises on a smaller scale in legal theory, where the problem of incommensurability (equated, rightly or wrongly, with incomparability) has been offered as a rebuttal to Ronald Dworkin's theory of law, a theory that depends on (judges) being able to combine two (or more) quite disparate values in determining the relative merit of two interpretations of past legal decisions. See Brian BIX, LAw, LANGUAGE, AND LEGAL DETERMiNACY 96-104 (1993); John Finnis, On Reason and Authority in Law's Empire, 6 LAW \& PHIL. 357 (1987); John Mackie, The Third Theory of Law, in RONALD DWORKIN AND CONTEMPORARY JURISPRUDENCE 161, 164-65 (Marshall Cohen ed., 1984). To the extent that my text, above, endorses an equation of incommensurability and incomparability, I hereby withdraw the claim, for the reasons given succinctly in Chang, supra note 1, at 13-34. 
judgment. Any automaton can choose $\$ 500$, when the alternative is $\$ 100$; and similarly if one way of life "equals" 5000 "units of happiness/contentment" while an alternative way of life "equals" only 1000 units. ${ }^{7}$ The difficult choices in life are not like these; they involve a sense that whichever way one chooses, one will be giving up something of significant value. Incommensurable choices are the choices that are later viewed with some regret, or even labeled as "tragic," even when one continues to believe the choice made is the correct one. ${ }^{8}$ For example, one reasonably might choose to spend more hours working in order to create greater economic security and opportunity for one's family, but might regret (both now and later) the lost chance to spend more time with one's family.

The two articles on which I am commenting for the most part stay clear of such general reflections on the nature and consequences of incommensurability, considering instead what implications might follow once we accept the irreducible plurality of values. Bruce Chapman, in Law, Incommensurability, and Conceptually Sequenced Argument, ${ }^{9}$ tries to show how our decisionmaking processes often find ways to give plural values distinct and ordered consideration, and how legal decisionmaking may offer a number of particularly effective instances of this possibility. Leo Katz, in Incommensurable Choices and

${ }^{7}$ See John Finnis, Concluding Reflections, 38 Clev. ST. L. REV. 231, 234-41 (1990); James Griffin, Incommensurability: What's the Problem?, in INCOMMENSURABILITY, supra note 1 , at 36 . Finnis writes:

For the whole point of my argument about the relation between incommensurability of options and rationally motivated, morally significant free choice is that if one option dominates the others (i.e., offers unqualifiedly greater good or lesser evil), the others cease to have rational appeal; but morally significant, rationally motivated choice is between alternative options each of which has rational appeal; therefore where one option is dominant, deliberation ends not in choice but in insight (into the unqualified rational superiority of that option) and action.

Finnis, supra, at 236 (footnote omitted).

${ }^{B}$ See Sunstein, supra note 5, at 859-60 (connecting incommensurability and the sense of tragedy). For those who believe that incommensurability entails incomparability, it is even easier to understand the tragic aspect of incommensurable choices. Bernard Williams wrote the following regarding Agamemnon's choice between the expedition to Troy and the life of his daughter:

The agonies that a man will experience after acting in full consciousness of such a situation are not to be traced to a persistent doubt that he may not have chosen the better thing; but, for instance, to a clear conviction that he has not done the better thing because there was no better thing to be done.

BERNARD WILLIAMS, PROBLEMS OF THE SELF 173 (1973).

${ }^{9}$ Chapman, supra note 4 . 
the Problem of Moral Ignorance, ${ }^{10}$ demonstrates some difficulties in one usual understanding of incommensurability, and also uses incommensurability as a starting point for an inquiry regarding moral intuitions, deontological logic, and the criminal law. I will discuss the articles in turn, offering in passing some reflections on the connections between the two.

\section{SEEKING, ORDERING, AND AVOIDING ISSUES}

Professor Chapman takes as his starting point that values are plural and that some sets of values are incommensurable. He notes that this already puts him at odds with traditional economic analysis and rational choice theory. Those approaches assume that all options can be ordered based on people's preferences: Even if we claim to be unable to choose between, say, friendship and money, or to reduce one to the terms of the other, our choices belie our assertions. By being willing to break a lunch date with a friend to pursue a lucrative opportunity, but not being willing to break the appointment for a far less lucrative opportunity, we have, the argument goes, begun to specify the dollar value of that friendship. Similarly, by being willing to accept an increased risk of death in exchange for an increased pay, with sufficiently subtle calculation, we can figure out how much our lives mean to us. " Many writers have argued that this inference and equation is not justified. ${ }^{12}$ While Chapman does not focus particularly on that debate, his article opposes the foundational assumptions of economics and rational choice theory in another, perhaps more indirect way: by showing that the consideration of plural values in a noncommensurating way is both common (in both individual and institutional decisionmaking) and sensible.

Chapman's portrayal of "conceptually sequenced argument" offers an alternative to two different sets of traditional (economic)

${ }^{10}$ Leo Katz, Incommensurable Choices and the Problem of Moral Ignorance, $146 \mathrm{U}$. PA. L. REV. 1465 (1998). This is familiar territory for Professor Katz, who is a master of elucidating and justifying the paradoxes of deontological reasoning, in particular as they occur in criminal and moral culpability. See, e.g., LEO KATZ, BAD ACTS AND GUILTY MINDS (1987); LEO KATZ, ILI-GOTTEN GAINS (1996).

1 See, e.g., Richard A. POSNER, ECONOMIC ANALYSIS OF LAW 216 (5th ed. 1998) (discussing the valuation of life in terms of wage premiums in risky occupations and tradeoffs between safety and cost).

${ }^{12}$ See, e.g., Sunstein, supra note 5, at 797-98 (offering reasons for rejecting the concept of "revealed preferences").

is See Chapman, supra note 4, at 1492-95. 
positions. First, regarding the commensurability of values: (a) many argue that there is only a single value or that all values can be effectively combined in a single evaluation; and (b) those who recognize problems with commensurating some values often hold out as the only alternative the lexical ordering of values, in which one value has absolute priority over the other(s). Against those positions, Chapman argues that we can accommodate plural values in a decision procedure, without either assuming that they can be commensurated on a single metric or requiring that one value always maintain absolute priority over others (that is, allowing for at least a limited tradeoff of values). Second, when values or criteria are applied in a sequence, the conventional view appears to be that there can be no reason or order in the way that a series of evaluations is done. ${ }^{14}$ Here, Chapman's contrary position is that there can be reason for choosing one partition rather than another, and one path rather than another, in creating a sequenced decision.

Chapman's position is that although there is no way sensibly to combine plural values in a single evaluation, one can have a multipart evaluation that gives a number of different values their individual due. Additionally, in creating the multiple-step process of evaluation, some ways of partitioning the items to be evaluated, and some ways of ordering the types of evaluation, will be better than others. ${ }^{15}$

For some people who work within rational choice theory, one of the most contentious aspects of Chapman's article is his conclusion, partly argued for and partly assumed, that there are (or can be) failures of transitivity in people's preferences, and that these failures, when they occur, are or can be sensible (that is, not "irrational"). ${ }^{16}$ While I note the importance of the issue and the possibly controversial nature of Chapman's position, I must leave that issue to others. To the extent that taking a position is essential for the purposes of my argument, this Comment will side with Chapman by assuming that there is intransitivity, and that such intransitivity is not necessarily irrational.

Chapman illustrates how the sequence in applying criteria of selection sometimes affects the evaluations, in the sense that different orders will yield different outcomes. ${ }^{17}$ He gives the example of the

14 See id. at $1490,1493-94$.

15 See $i d$. at $1492-507$.

${ }^{16}$ See id. at 1496-507.

${ }^{17}$ See id. at 1493 ("Different sequences [of consideration of the different criteria] will often determine different final outcomes."). 
diner whose dessert choice will vary depending on the order in which pairs of fruit are offered to her. The differing outcomes derive from whether the value of etiquette is presented, which will occur if, and only if, the diner must choose between a small apple and a larger one. In such a circumstance, the value of etiquette overrides hedonistic values, and the diner would choose the smaller apple. If the fruit is presented in a different order, the choice between different-sized apples would never arise, and a different overall outcome would result. ${ }^{18}$

This sort of situation presents the issue squarely, as Chapman notes: ${ }^{19}$ We sometimes can structure choices in ways that avoid reaching certain values or questions, or in ways that expressly seek to consider and confront such values or questions.

Is there thus a general principle that we should try to structure our (individual, institutional, or social) decisions in such a way that all issues (values) that might be raised will be raised? Is it the case that since one way of partitioning the dessert-choice problem would raise issues of etiquette, selection procedures or partitions that invoke etiquette are to be preferred to ones that do not? This seems to be Chapman's position, ${ }^{20}$ and there is a sense in which that approach, at least as an ideal (limited by the constraints of time, resources, and imagination), seems right. However, we must consider at least two responses to this intuition.

First, we encounter a practical problem: As with choosing a dessert in a selection among three choices, the number of possible issues may be small and manageable; however, when the choice is among a larger number of more complex options (which career path to choose, or which candidate among a dozen should be given a scholarship), numerous issues which could be considered (and which might become salient if just the right pair of alternatives were combined)

${ }^{18}$ See id. at 1498-99, 1503-05. As was pointed out by a number of people at the Symposium, the etiquette example is peculiar because the rule of etiquette can be reduced to "do not take the best dessert-the one you prefer (actually, more precisely, the one that is conventionally more preferred)-for that would seem too selfish." Thus, the etiquette rule is to choose against your (likely) preference. As the "etiquette" value works as a kind of "antipreference," it is not surprising that it creates disruptions of earlier stated preferences. Still, Chapman's general point, that some partitionings of choices will raise issues that would remain "hidden" under alternative partitionings, and that these additional issues could affect the ultimate outcome, can survive through other examples.

${ }^{19}$ See id. at 1503-04.

${ }^{20}$ See id. at 1503 ("Avoiding these apparent dangers by avoiding the relevant choice partitions also, unfortunately, appears to avoid what may really be at issue."). 
may exist. ${ }^{21}$ So there are practical difficulties, at the least, for the general proposition that we should try to tease out all possible values and issues.

The claim is meant obviously to resonate with other sorts of choices, such as the scholarship-selection problem. With the scholarship-selection problem, as set out by Chapman, there are three criteria put forward, all of which seem "genuinely relevant to what [is] at stake." ${ }^{23}$ However, the scholarship example is problematic in a different way. When it is introduced, the reader is told simply that these three criteria (financial need, scholarly ability, and community service) are the bases on which the candidates are to be assessed. ${ }^{24}$ All three criteria are thus "genuinely relevant" to the ultimate selection by prior stipulation.

Most decisions do not come to us prepackaged in that way. We do not know ahead of time which issues "must" be considered, nor do we usually know at the start which values will be raised. However, it may be that the absence of prepackaging is not important for most people most of the time. Someone agonizing over whether to become an artist or a physician is likely to have thought through all the values instantiated by either path. Similarly, one might argue that a well-trained lawyer or judge will be able to tease out all the issues raised by a set of facts brought for legal evaluation.

${ }^{21}$ In Chapman's scholarship example, see id. at 1487, the three values that the committee will consider already have been determined before the selection process has begun. However, imagine a similar committee given the instructions merely to choose "the best" or "the worthiest" candidate. That committee, either before or after looking at the applications from the students, could come up with a much longer list of possibly relevant criteria.

${ }_{22}$ There is a connection to be drawn here with some points in Katz's article. In the criminal law's judgments of culpability, multiple values are simultaneously served: at the least, both the focus on the badness of the (intended) act itself and a focus on the consequences of the completed act. See Katz, supra note 10, at 1482-84; see also infra Part III. Additionally, either the criminal law itself or sentencing guidelines introduced independently of the substantive law is likely to bring into account considerations of individual deterrence, general deterrence, and rehabilitation.

First, it is inevitable that not all possible values that might be raised by questions of liability and punishment are in fact considered. Second, using the terms of Chapman's analysis, the values that are considered are partly mixed together without clear separation, and partly subject to an ordered sequence (for instance, initial judgments of criminal liability tend to be more deontological, while the sentencing phase tends to allow more utilitarian considerations and also considerations of individual mercy and compassion).

${ }^{23}$ Chapman, supra note 4, at 1503.

${ }^{24}$ See id. at 1487. 
There may be other occasions, though, where we are less sure, often because we are carrying out instructions that are too vague or too general ("pick the best student" and "pick the best person for the job" may or may not be too general in this way, depending on how much help the chooser can find from the specific context).

A second problem with the claim that we should structure our decisions in such a way that all possible issues (values) are raised is that sometimes we consciously avoid considering issues (and we sometimes have good reasons for doing so). For example, it is commonly stated (and perhaps stated more often than followed) in American legal decisions that courts should, whenever possible, avoid facing and deciding a constitutional question, even if the constitutional question might, in other ways, be a more straightforward way of deciding the dispute. $^{25}$

Chapman's response to the possibility of using partition to avoid issues is that such an action "appears to avoid what may really be at issue." ${ }^{26}$ However, this claim immediately follows a long discussion of the dessert-choice problem, and, as Chapman notes, ${ }^{27}$ it is hard to perceive the sense in which etiquette is "really ... at issue" in choosing a dessert. If the selection is offered in an order that happens not to raise the issue, it is hard to see how anything important has been lost. In other contexts, including cases implicating constitutional questions, I remain doubtful that issues "must" or "should" always be confronted simply because they are present, or even because they are saliently present. Sometimes there are important countervailing considerations counseling us to avoid issues and to avoid choice.

${ }^{25}$ See, e.g., JOHN E. NOWAK \& RONALD D. ROTUNDA, CONSTITUTIONAL LAW 88-90 (4th ed. 1991) (discussing the Supreme Court's rationale for avoiding constitutional questions if possible). More mundane examples abound. Those who are wise will go far out of their way to avoid issues where any answer, or any truthful answer, might get them into great trouble. An example of one such question is, "if you could only save one from drowning, and it was either your dog or me-or your mother and me, or your best friend and me-whom would you save?" In more public decisions, the choices may be partitioned and sequenced in a way that minimizes or avoids entirely the chance of awkward or controversial issues arising, or that seeks to circumvent possible appearances of impropriety.

${ }^{26}$ Chapman, supra note 4, at 1503 (emphasis added).

${ }^{27}$ See id. ("We may feel that there is less danger of this [avoiding what is really at issue] happening in the dinner party example than in the scholarship example."). 


\section{TESTING FOR INCOMMENSURABILITY (INCOMPARABILITY)}

In the first part of his article, Professor Katz uses examples to show how one standard test for incomparability, that given by Joseph $\mathrm{Raz}^{28}$ does not seem to work. ${ }^{29}$ Raz's test, to which Katz refers regularly in his article, states that two items or options are incomparable if it is known that neither is better than the other, and "[i]f it is possible for one of them to be improved without thereby becoming better than the other, or if there can be another option which is better than one but not better than the other."

Katz offers the example of irregularly shaped pieces of paper, ${ }^{31}$ in which two pieces of paper with similar irregular shapes (looking like the state of Idaho in outline) can be compared easily with respect to their area, but neither can be judged easily against a third piece of paper with a quite different shape (like, for example, the state of Texas). This example seems to fit Raz's definition, "a failure of transitivity," incomparability (or incommensurability). It is an epistemic problem: Although we have trouble judging the area of these shapes, there is nothing that looks like "incommensurability" or "incomparability"; we have no suspicion that we cannot eventually judge one to be larger than the other, or that the two pieces of paper cannot be measured on the same metric, such as "square inches" or "square centimeters."

This example also is distanced from our usual understanding of incomparability, or incommensurability, by its "feel": There is no perception of irredeemable loss or tragic choice in the selection. ${ }^{34}$ In $_{35}$ this sense, Chapman's example of selecting between fruit for dessert ${ }^{35}$ also seems to be too distant from the core cases of incommensurability to be fully helpful in our exploration of the concept.

${ }^{23}$ See Katz, supra note 10, at 1465; see also RAz, supra note 2, at 325-26. Although both Raz and Katz describe the object of discussion as "incommensurability," it is what is being called "incomparability" in this Comment, and for convenience and consistency, I will use the latter term when referring to Raz's test.

${ }_{29}$ It is possible that presenting this critique is not Katz's purpose. In the spirit of his article, however, I am happy to give Katz the credit for the beneficial results, whatever the original motive.

so RAZ, supra note 2, at 325.

s1 See Katz, supra note 10, at 1466-67

${ }^{32} \mathrm{RAZ}$, supra note 2, at 325.

ss See supra notes 1-2 and accompanying text.

${ }^{34}$ See supra notes 7-8 and accompanying text.

${ }^{35}$ See Chapman, supra note 4, at 1498-99. 
The irregularly shaped paper example, as well as the example of the plaintiff who fails to meet her burden of proof, allows Katz to show how Raz's test seems to fail to distinguish the specific problems of incomparability, or incommensurability, from the more general (and less troubling) phenomenon of indeterminacy. ${ }^{37}$ We might have many reasons for having difficulty comparing two items. If the reason is just a matter of inconvenience (we cannot "eyeball" the difference in area between the two irregularly shaped pieces) rather than true incommensurability or incomparability, then minor variations will not overcome the problem of comparison, but great variations will. For example, if the old "Idaho-shaped" piece of paper is replaced by a similarly shaped piece four times as large, we no longer will have any doubts about whether it is larger than the "Texas-shaped" piece of paper. Similarly, if we add not a "smidgeon" to the plaintiff's case, but instead a substantial amount of evidence (and assuming that the defendant still does not reply), the judge properly will decide in the plaintiff's favor. ${ }^{38}$

${ }^{36}$ See Katz, supra note 10, at 1466-67. It is interesting to note that the burden of proof shows up in both of the subject articles, but for quite different purposes.

For Katz, the initial burden of proof indicates an existing situation of indeterminacy between the parties (which he describes as an instance of incommensurability or incomparability, but I would not). See id. at 1467. Of course, it also would be possible to characterize what is going on with initial burdens of proof in a quite different manner, one that would not invite possible claims of incommensurability or incomparability. One could argue that there is an institutional decision that it is for the plaintiff to make out a case sufficiently so that we can believe her, and unless she does, the defendant automatically wins. Once the plaintiff has made out a sufficient case, whether the defendant responds or not, then and only then will the judge even attempt to adjudicate between the competing versions of what happened.

Chapman, discussing defeasibility in legal concepts, uses shifting burdens of proof to show how the law (with such examples as contract law, criminal law, and tort law) effects a reasoned application of plural values. See Chapman, supra note 4, at 1507-26; see also Claire Oakes Finkelstein, When the Rule Swallows the Exception, in RULES AND REASONING (Linda Ross Meyer ed., forthcoming 1998) (arguing that exceptions to rules (such as some of the affirmative defenses to criminal liability) are often best understood as expressing the incommensurable values instantiated in different rules and principles).

${ }^{37}$ See Regan, supra note 2, at 1058-61 (arguing that a person's agonizing over a choice between a life as a clarinetist and a life as a livestock farmer more likely reflects the difficulty of working out a solution rather than the impossibility of such a solution due to incomparability).

${ }^{38}$ As Katz wrote: "Every time a plaintiff backs his complaint up with evidence, he turns an incommensurable choice into a commensurable one." Katz, supra note 10, at 1468. Once one substitutes "incomparable" for "incommensurable" in Katz's text, it is clear that he is making the same point I am making above: that a choice that looked like it might involve incomparable items can be shown to be comparable if one greatly increases the value of one of the items. 
The subjective construction of Raz's test ( $m$ y inability to choose between $a$ and $b$; and $m y$ preference of $c$ over $b$, but inability to choose between $a$ and $c$ ) in a sense invites the conflation of true incomparability (or even mere incommensurability) and more mundane epistemic difficulties. ${ }^{39}$ Additionally, it invites Katz to try to find incomparability or incommensurability not only in choices among options, but also in the construction of beliefs (such as determining whether proposition $X$ is true or false), when the concepts do not seem to fit. ${ }^{40}$

Although the above argument is meant to help us distinguish general problems of indeterminacy from true problems of incommensurability or incomparability, Ruth Chang has offered a similar analysis to show why incommensurability does not entail incomparability. ${ }^{41}$ We may have trouble comparing two great artists (say, Rembrandt and Mozart), in order to say that one was the "greater artist," when the two artists' work instantiated quite different values in quite different genres. The incommensurability of the values instantiated in classical music and high Renaissance painting, however, would not necessarily stop comparison if we were to compare Rembrandt not with Mozart, but with a fourth-rate composer of little skill and less creativity. Most of us would have no trouble concluding that Rembrandt was the greater artist. However, if Rembrandt is comparable with the least of the classical musicians, it is hard, conceptually, to understand how he would not be comparable with someone higher on the same scale. ${ }^{42}$

${ }^{39}$ The fact that the focus on subjective preferences might cause analytical confusions has been pointed out, in the context of a quite different critique, by Donald Regan. See Regan, supra note 2, at 1057-58.

${ }^{40}$ See, e.g., Katz, supra note 10 , at 1467-68. The example of the judge determining which version of the facts is correct also seems to fall within this category. See id. at 1467. These are not cases of insufficient evidence (that is, "ignorance") hiding as incomparability; rather, they are cases simply of insufficient evidence always understood as such.

1 The remainder of this paragraph draws on Chang, supra note 1, at 1416.

${ }^{12}$ It might be argued that what distinguishes Mozart from his lesser colleagues is this amorphous thing called "genius," and that is why the lesser musician will be on a different scale than a genius of painting like Rembrandt. Without commenting on the nature of genius, or on the effects it has on the commensurability and comparability of artists, I simply would suggest an amendment of the example. Contrast instead, on the one hand, highly skilled artists who fall short of genius, and, on the other hand, artists of very little skill. I believe the conclusion would be the same: The doubts we have of comparing highly skilled artists of different forms or genres would fade if we were comparing instead a highly skilled artist with a distinctively unskilled artist. As Derek Parfit once wrote, "There can be true comparisons even across quite different arts, or cultural traditions. Rembrandt and Bach are in the same league [that is, are 
Once incommensurability and incomparability are disentangled, some of Katz's more interesting points can be seen with greater clarity. For example, consider the discussion of the different reactions to the "evil deity" who brings great benefits at the cost of 1000 lives intentionally taken, as against the invention of the automobile, which brings many more deaths, but in an unintentional way. ${ }^{43}$ People are able to compare in terms of culpability the smaller number of deaths intentionally caused with the much larger number unintentionally caused--usually holding the intentional takings of life worse than the unintentional, even though the former involves a far lower number of lives lost. ${ }^{44}$ This is a comparison of items that appear to be on different "metrics" (intentional killing versus death as unintended sideeffect); yet we seem able to make comparisons of culpability. ${ }^{45}$ The argument is that "intentional bad acts" constitute (at least) one scale and "unintentional bad acts" another. There obviously might be room for further subdivisions (for example, in each case, acts versus omissions); if so, these only would increase the incommensurability of various bad acts. Yet, when we come to judgment, however easily or with difficulty these judgments come, regarding the relative culpability of bad actions (some intentional, some unintentional), we have reason to believe that these actions are not incomparable.

"imprecisely equal']; and both are greater than Jeffrey Archer." Derek Parfit, Letter, Isaiah Berlin, TIMES LITERARY SUPPLEMENT, July 19, 1991, at 13.

43 See Katz, supra note 10, at 1472-73 (discussing a hypothetical from GUIDO CALEBRESI, IDEAS, BELIEFS, ATTITUDES AND THE LAW 1 (1985)).

${ }^{41}$ On the arguments for holding an intended result as far more culpable than one brought about as a side-effect, even a side-effect clearly foreseen, see, for example, John Finnis, Intention and Side-Effects, in LIABILITY AND RESPONSIBILITY 32, 61-64 (R.G. Frey \& Christopher W. Morris eds., 1991).

${ }^{45} \mathrm{It}$ is both interesting and important to note that as long as the number of deaths is not too disproportionate, there tends to be a consensus, or nearly so, on the intentional taking of life being more culpable. As Katz would point out, this indicates the deontological nature of our moral intuitions. See Katz, supra note 10, at 1473-75. At some point, though, as we increased the differential, with the number of deaths unintentionally caused becoming vastly greater than the number caused intentionally (for example, one million as against 10), some people might "defect" to the conclusion that the unintentional taking of life was, in this instance, more culpable. Those defections would not, however, undermine either the conclusions about the incommensurability and incomparability of the choice, or the conclusion about our deontological intuitions. 


\section{DEONTOLOGY, MORAL LUCK, AND INNOCENCE}

The second part of Katz's article considers how we should treat reasonable mistakes of judgment for the purpose of moral and legal culpability. This is largely independent of the first part of the article, as the treatment of culpability, according to Katz, does not turn on whether our mistakes are based on a false attribution of incommensurability/incomparability or some other reasonable mistake. The line of significance for Katz, instead, lies between mistakes in matters of fact and mistakes in matters of morality (or law).

Katz argues that the criminal law (and morality) usually will excuse "unavoidable" factual ignorance, but not "unavoidable" moral ignorance. ${ }^{46}$ In such situations, by hypothesis, the actor has done as well as she could; it is bad luck (not, by hypothesis, bad judgment) that the choice made turned out to be the wrong one. Under such circumstances (at least as characterized thus, abstractly), Katz concedes that, for many of us, our initial reaction might be that the actor should not be blamed. ${ }^{47}$ However, as he points out, there appear to

${ }^{16}$ See id. at 1476-77. In talking about these matters, Katz clearly means "reasonable factual or moral ignorance/mistake," even if this is not always clearly stated. It is one thing if I do not know (and could not have reasonably been expected to know) that you are hiding behind the curtain at which I am shooting. See id. at 1476. It is, of course, quite another matter if I claim not to know that shooting a gun can cause severe injuries. Even if that is in fact my state of ignorance, it is not a reasonable mistake.

As for the person who did not know that lethal force could not be used in defense of her property, see id., one might first ask (as a matter of nonlegal, moral culpability) whether that ignorance/mistake was reasonable. We might explain the law's refusal to accept "ignorance of the law" as an excuse as being based on a conclusion (perhaps encouraged by policy reasons concerned with creating the right incentives, see $i d$. at 1476-77) that ignorance of the law is never reasonable. Cf. id. at 1477 (contrasting those who would criticize the subjects in the Milgram experiment for being culpably ignorant of what morality required, as against those who would criticize the subjects despite allowing that the subjects' moral ignorance was excusable).

However, I think Katz adds an unnecessary and potentially confusing level of complexity when he offers Mao and Stalin as paradigm cases for our moral sympathy. See id. Even assuming for the purposes of this argument that both tyrants sincerely believed that their actions were morally correct, that does not automatically make their moral mistakes "reasonable" (or "unavoidable"). Reasonableness is one defense, and usually has been understood as an objective test; subjective sincerity is a quite different defense, one which brings up different moral questions, even though the sincere wrongdoer and the reasonably mistaken wrongdoer might both arguably fit the description of "someone who was 'not able to do better."

${ }^{17}$ See id. at $1476,1478-79$. 
be situations in which the law or morality blames (or blames more heavily) based on just such decisions. ${ }^{48}$

In the law, this attitude toward unavoidable moral ignorance, in particular the refusal to allow ignorance of the law as an excuse, might be justified on other grounds (for example, as standards meant to create proper incentives for citizens, or meant to overcome problems of proof). ${ }^{49}$ However, Katz does not want to use such "excuses"; he wishes to argue that the punishment of decisions made "in a state of unavoidable ignorance ${ }^{\mathrm{N5}}$ is morally defensible.

By morally defensible, he means, at a minimum, that moral and legal culpability in such situations would be consistent with or entailed by other judgments we find acceptable, or that they could be traced to foundational aspects of deontological moral thought. In Katz's terminology, punishing unavoidable moral ignorance (but not unavoidable factual ignorance) is "but one manifestation of a more general, highly counterintuitive, aspect of deontological morality."

Katz offers two examples, both of which are instructive. First is the example of the two General Douglas MacArthurs: the real one who "wrongly" went out into battle and won glory (and many medals), and the hypothetical second one who had "rightly" stayed on the general staff, but thereby won little, if any, glory. ${ }^{52}$ Two concepts need to be unpacked to evaluate this example better. First, Katz contends that medals and like honors "pretty well track[] moral achievement."53

${ }^{48}$ See id. at 1476-78, 1481-84.

${ }^{49}$ See id. at 1477-78 (mentioning a similar argument).

${ }^{50} I d$. at 1476 (capitalizations omitted).

51 Id. at 1481.

52 See id. at 1481-82.

${ }^{53}$ Id. at 1481 . I will assume as much for the purpose of argument, but I am far from persuaded. Often our considered moral evaluations of people and deeds do not necessarily correlate with the initial distribution of fame and praise. Medals and public praise go to those who do showy things in public places; one might argue that there are matters worthy of equal or greater moral praise going on in less showy ways and in less public places. Compare the comments about the protagonist Dorothea at the end of George Eliot's Middlemarch:

Her finely-touched spirit had still its fine issues, though they were not widely visible. Her full nature, like that river of which Cyrus broke the strength, spent itself in channels which had no great name on the earth. But the effect of her being on those around her was incalculably diffusive: for the growing good of the world is partly dependent on unhistoric acts; and that things are not so ill with you and me as they might have been, is half owing to the number who lived faithfully a hidden life, and rest in unvisited tombs.

GeORGe Eliot, Middlemarch 825 (David Carroll ed., Oxford Univ. Press 2d prtg. 1992) (1872). 
Second, the decision to go into battle was "wrong" in the sense that it was thought by some that MacArthur could have saved more lives in the staff position.

Katz's point is that the hypothetical MacArthur, who stayed on the general staff, "blackened his moral ledger" ${ }^{\text {"54 }}$ by doing so, even though it was the "right" decision. ${ }^{55}$ Thus, there are times when choosing the wrong way can lead to praise, or choosing the right way can lead to blame, because of what comes later. The wrong or immoral choice might lead, by the vagaries of chance, to an opportunity for a highly praiseworthy act; or, the actor may have foreseen that the wrong/immoral choice is a necessary first act on the path to the highly praiseworthy act; or, the wrong/immoral choice somehow leads to good consequences in the world. ${ }^{56}$ In all of these cases, our moral intuitions might be that the person who made the initial wrong choice nonetheless should be praised (and praised more than the person who initially made the moral/right choice) because of what came later.

Katz's point seems to be that since bad choices can lead (in the long run) to a better moral evaluation, and, thus, conversely, good decisions can lead to a lesser moral evaluation, we should not be surprised that sometimes a seemingly morally neutral act (like making an unavoidable moral mistake) leads to justified blame.

These points are even clearer in Katz's second example, involving the two villains who each commit a series of heinous acts (which put five people in conditions that would be fatal if untreated), with the second villain then doing one additional act that we would all consider illegal and immoral (killing a sixth person to harvest that person's organs). ${ }^{57}$ However, the effect of the additional act is to reduce the consequences of the prior series of heinous acts (the organs from the sixth victim are used to treat the other five), thus apparently making the second villain subject to lower criminal and moral culpability even though he seems the worse actor, having done everything the first villain has done, plus one more bad deed (the first villain ends up the murderer of five; the second a murderer of one, with only attempted murder charges against the other five).

\footnotetext{
${ }^{54}$ Katz, supra note 10, at 1484 (emphasis omitted).

${ }^{35}$ Id. 1483.

${ }^{56}$ These possibilities are meant to cover the examples Katz gives later. See id. at ${ }^{57}$ See id. at $1482-83$.
} 
Katz presents this example to remind us of the paradoxes of moral and legal thought, paradoxes often, as here (according to Katz), based on the deontological nature of much of criminal and moral thinking. ${ }^{58}$ If it seems to us clearly wrong to punish less severely a person who has clearly done a greater amount of harm, and, if our moral intuitions thus clash with certain moral principles, one reasonable response would be that those purported moral principles (and legal principles) should be questioned. Thus, my first inclination in responding to Katz's example, and his claim of what deontology "requires," was to say: "well, so much the worse then for deontology (and any criminal law that follows it)."

On further reflection, I am not even sure that the position Katz is defending is even properly understood as "deontology." the label is not important. Labels aside, we can distinguish important differences of emphasis: (1) when culpability or punishment is based entirely on the will of the actor (on what she intended); (2) when culpability or punishment is based in part or entirely on the consequences of the act; and (3) when punishment is based in part or entirely on the general consequences (on the defendant or on society in general) of imposing this punishment rather than another one. My point is simply that while many people who call themselves Kantians or deontologists would prefer the first approach, Katz has argued that our legal system and our moral intuitions tend to follow the second approach (which incorporates "moral luck," a concept discussed below $\left.^{60}\right)$. He further claims, or at least strongly suggests, that this is in fact the morally correct approach. I have no argument with the descriptive claim that an attention to consequences of the act is, often, part of our conventional moral and legal practices. Because I have some sympathy for the first approach (attention only to the actor's will, attention only to the rightness or wrongness of the act), I remain uncertain about the prescriptive/critical claim. ${ }^{61}$

${ }^{38}$ See, e.g., id. at 1483 ("[T]his sort of thing is an inevitable feature of deontological moral reasoning.").

${ }^{59}$ For one example of Kant's thoughts on punishment, see IMMANUEL KaNT, THE METAPHYSICS OF MORALS 140-45 (Mary Gregor trans., Cambridge Univ. Press 1991) (1797). For a comprehensive overview of deontology, see Heidi M. Hurd, What in the World Is Wrong?, 5 J. CONTEMP. LEGAL IsSUES 157 (1994).

${ }^{60}$ See infra notes 62-65 and accompanying text.

${ }^{61}$ The third approach described above is what is usually called the "utilitarian" or "consequentialist" approach to punishment. See H.L.A. HART, PUNISHMENT AND RESPONSIBILITY 18-21 (1968) (discussing a utilitarian approach to punishment). 
One problem for a purely deontological approach is that of moral luck. $^{62}$ The concept is explained concisely by Simon Blackburn: "In the Kantian tradition, a person's moral worth depends only on the quality of their will, and is thus independent of external circumstance. But reflection shows that our ordinary estimates of persons may depend greatly on external matters, and even matters of chance." ${ }^{, 63}$ For example, imagine that three people are driving with equivalent recklessness: The first hits another car, killing its occupants; the second hits another car, causing significant but not lifethreatening injuries to the occupants; and the third somehow manages to arrive home without causing damage or injury. As per a Kantian or deontological analysis of the wrongness of action, all three are equally culpable. ${ }^{64}$ However, the criminal law, which pays close attention to consequences, will punish the three with quite different penalties, a result that seems simultaneously consistent with and at tension with the moral intuitions most of us hold. ${ }^{65}$ So it is with Katz's two villains: One has done an additional immoral deed but will get the lighter punishment because the ultimate consequences are less severe.

${ }^{62}$ See, e.g., THOMAS NAGEL, Moral Luck, in MORTAL QUESTIONS 24 (1979); BERNARD WILIIAMS, Moral Luck, in MORAL LUCK 20 (1981).

${ }^{6}$ THE OXFORD DICTIONARY OF PHILOSOPHY 251 (Simon Blackburn ed., 1994) (defining "moral luck").

${ }_{6-1}$ A similar analysis is offered in Hurd, supra note 59 , at 187-88, 195-96.

One might try to argue that the different consequences are conclusive evidence of the different levels of recklessness of the drivers, but this conclusion, especially as a generality for all cases of this sort, is not a persuasive description of the world. Imagine two assassins both trying to kill important political leaders. One succeeds and is thus guilty of murder. The second does not succeed, and is therefore guilty of a much lesser charge, but the failure may have been due to all sorts of fortuitous circumstances unrelated to the person's culpability-for example, a defective bullet, the intended victim unexpectedly bending over, and the like. Consequences in life are often the results of fortune, not merit, and the only question is how the law and morality should respond to this fact.

Finally, one might argue that reckless driving that results in death is simply "a different act" than reckless driving that ends only in serious injury and reckless driving that does not cause injury at all. This attempted "solution through characterization" merely serves to hide the moral problem. It does not solve the problem, for the question still remains why one driver should be punished far more severely than another when the extent of their deviation from proper behavior is identical.

${ }_{65}$ Even most of those committed to deontological principles of culpability concede that deontological thinking constitutes only a part of the justifications regarding legal (tort and criminal law, in particular) and moral culpability. See, e.g., Heidi M. Hurd, The Deontology of Negligence, 76 B.U. L. REV. 249, 253-54 (1996). 
There is one response that must be considered first. The difference between my example of the three reckless drivers and Katz's example of the two villains is that in my case, the differences in ultimate consequences are accidental (hence the phrase "moral luck"), while in his case the differences are intended (the sixth person is killed in order that the previous five victims could be treated). This is a contrast of possible significance: Katz's second villain may deserve our praise for trying to reduce the death toll of his actions, at the same time that he earns additional blame for the immoral means he has chosen for attaining that result. However, Katz is not emphasizing the good intentions of the second villain, but rather only the good results. His example would come out the same way if the second villain's additional immoral act had led accidentally to the saving of the previous five victims. Katz's point is about bad acts and (ultimately) good results, not about bad means being justified by a good end (an unlikely view for a committed deontologist). ${ }^{66}$

If the system of blame or liability were purely deontological, ${ }^{67}$ the issue would be simple: Both villains had done the same five evil deeds, but the second villain had added a sixth evil deed, and therefore should be subject to greater blame and liability (a greater blame and liability that might be mitigated, but that would not be removed entirely, by the good intention with which the act was done).

What does any of this have to do with "unavoidable moral mistakes"? The basic structure of Katz's argument seems to be this: If a right decision can lead to greater blame (or its equivalent, lesser praise), then a morally neutral decision, like an unavoidable moral mistake, can also, on occasion, legitimately warrant blame. There is a danger of a reductio ad absurdum: If good actions sometimes lead justifiably to blame, then any kind of action justifiably could lead to

${ }^{66}$ This sixth bad deed cannot, under classical deontological system, be justified by its intended good end. See, e.g., Katz, supra note 10 , at 1483 (making a similar judgment about the bad act $A$ had done in order to be able to do good acts $B, C, D, E$, and $F$ ). Even if the intended good end somehow does negate or mollify the bad means, that simply alters our evaluation of the sixth deed. It does not, however, negate the fact that, under a deontological analysis, it is on the deeds themselves (in Kantian terms, the will itself) that we must focus, rather than on the consequences those deeds have in the world.

${ }^{67}$ In a complicated and interesting argument, Heidi Hurd tries to split the difference by distinguishing "theories of culpability" and "theories of wrongdoing," arguing that a theory that accepted moral luck and focused on the completed act might well be a defensible (and defensibly "deontological") theory of wrongdoing even if it were not a defensible (or defensibly "deontological") theory of culpability. Hurd, supra note 59 , at 193-96. 
blame. To clarify Katz's point, one would have to add: A morally good or neutral act can justify blame at some later point if that action causes or in some sense "leads to" bad consequences. Katz is thus reminding us of the importance of consequences to our moral intuitions and legal doctrines. This is an interesting and important conclusion, though it is a strange one to be emphasized by an advocate of deontology.

We all know that in life, making good choices does not guarantee that we will do better than someone who made foolish or evil choices. Life is not always fair. It would be quite another matter, however, to say that someone who acted in an evil way deserved better than someone who acted virtuously, or that someone who acted in a morally innocent way deserved more criticism than someone who acted wrongly. ${ }^{68}$ Where we find situations in which the above paradoxical circumstances occur (a less good action leading to greater public acclaim), at the least, explanation is called for. Depending on our attitudes towards the public response, either criticism or justification also would be in order.

Katz's argument appears to be that a less good action often leads to more favorable public and legal evaluation, and that these responses are justified morally. However, the justificatory argument is not stated clearly. The closest we come to an explicit argument is that this is what "deontological ethics" (as Katz understands that approach) requires. ${ }^{69}$ As I noted, this only invites the response: "So much worse for your deontological ethics!" Katz's other argument, more implicit than explicit, is that a situation of a less good action leading to greater acclaim occurs regularly because we share strong moral intuitions that allow such conclusions. We still need a moral argument, however, for why such conclusions should be acceptable (at least, an argument for why we should defer to commonly shared moral intuitions, however irrational or unjust they may at first appear).

Most troubling is Katz's argument regarding "unavoidable moral ignorance": that someone who has made a moral choice after making every possible effort to educate herself and to act reasonably could

${ }^{63}$ Where exactly the same action leads to quite different responses, in terms of praise, blame, or punishment, due to the consequences that follow from that action, that is the paradox of "moral luck," which was discussed supra notes 62-65 and accompanying text.

${ }^{69}$ See Katz, supra note 10 , at 1484 . 
still properly be subject to moral and legal criticism. ${ }^{70}$ In some narrow understanding of the concept, "deontological ethics" would evaluate actions based only on the nature of the act attempted and the nature of the act done, with no reference to the consequences that resulted from the act. ${ }^{71}$ However, even those who see deontology primarily as a side constraint on consequentialism run wild would argue that deontology at a minimum requires that people who are entirely innocent not be punished. ${ }^{72}$ In this sense, it seems that Katz's proposal is contrary to deontology, however understood. Under his hypothesis, we are asked to judge an actor who has acted under "unavoidable ignorance," someone who has not only done as well as she subjectively could have done, but has done as well as anyone could have done given the state of knowledge at the time. This seems like the definition of "innocent action." It is part of the commonly understood core of Kantian and deontological thinking that "ought implies can." Where no person could comply with a standard, failure to comply cannot be the basis for criticism or sanction. Yet Katz argues that this actor would-and should-still be punished because she, through no fault of her own, chose wrongly. There was no malice in the actor's intentions; there was no falling short in care or consideration. Punishing that actor may be justifiable on a moral theory grounded on consequentialism, but not on deontological grounds.

${ }^{70}$ See id. at 1476,1479 (providing an example in which the decisionmaker has done "the best he could" and "has consulted every philosopher and judge on an issue [and] followed their advice").

"See, e.g., Hurd, supra note 59, at 174-93 (describing two versions of this narrow form of deontological ethics).

${ }^{72}$ See, e.g., HART, supra note 61 , at 80 ("Much more important than these [qualifications] is the qualification which civilized moral thought places on the pursuit of the utilitarian goal by the demand that punishment should not be applied to the innocent; indeed, so insistent is this demand that no system of rules which generally provided for the application of punishment to the innocent would normally be called a system of punishment."). 